\title{
Educação inclusiva no Ensino de Química: uma análise em periódicos nacionais
}

Inclusive education in Chemistry Teaching: an analysis in national journals

Educación inclusiva en la Enseñanza de Química: un análisis en revistas nacionales

\section{Patrícia Maria de Sousa Santos}

Graduanda na Universidade Federal da Paraíba, João Pessoa, Paraíba, Brasil.

patriciamourah@hotmail.com

ORCID - https://orcid.org/0000-0001-9569-4735

\section{Pedro Henrique Pyrrho Nunes}

Graduando na Universidade Federal da Paraíba, João Pessoa, Paraíba, Brasil. phpnunes@outlook.com

ORCID - https://orcid.org/0000-0002-3248-7349

\section{Karen Cacilda Weber}

Professora doutora na Universidade Federal da Paraíba, João Pessoa, Paraíba, Brasil. karen@quimica.ufpb.br

ORCID -https://orcid.org/0000-0003-4823-5290

Claudio Gabriel Lima-Júnior

Professor doutor na Universidade Federal da Paraíba, João Pessoa, Paraíba, Brasil.

claudio@quimica.ufpb.br

ORCID - https://orcid.org/0000-0001-6570-8999

Recebido em 14 de fevereiro 2019

Aprovado em 26 de dezembro 2019

Publicado em 9 de março de 2020

\section{RESUMO}

O presente artigo apresenta os resultados de uma revisão bibliográfica da literatura online dos artigos publicados sobre a temática Educação Inclusiva em Ciências/Química em seis periódicos nacionais voltados para o Ensino de Ciências/Química. O acervo digital consultado totalizou 2.472 artigos publicados, no recorte temporal de 2006 a 2019 . Foram encontradas apenas 37 publicações relacionadas ao tema nos últimos treze anos. A seleção inicial dos artigos foi realizada a partir da leitura dos títulos e resumos de cada exemplar e volume publicado, incluindo edições especiais. As 37 publicações que se enquadram na temática foram lidas na íntegra, sendo qualificadas, quantificadas e agrupadas em tabelas e gráficos percentuais, a fim de identificar a periodicidade das publicações, levando em consideração a quantidade de artigos ao longo dos anos, a localização das instituições de origem dos autores, o nível de ensino, o enfoque temático e os tipos de deficiências consideradas. Por meio de uma abordagem quanti-qualitativa, verificamos: (i) baixo e desregular crescimento na taxa anual de publicações; (ii) concentração de publicações nas regiões centro-oeste e sul do Brasil; (iii) predominância de estudantes do ensino superior como sujeitos de pesquisa; (iv) a formação de professores como enfoque temático majoritário e (v) predominância de estudos sobre 
http://dx.doi.org/10.5902/1984686X36887

deficiência visual em detrimento de outros tipos. O panorama delineado revela a necessidade de uma ampliação na proposição e divulgação de atividades e materiais didáticos que auxiliem os professores em todos os níveis de ensino a lidarem com as demandas que se apresentam no âmbito da educação inclusiva.

Palavras-chave: Educação Inclusiva; Ensino de Química; Revisão de Literatura.

\section{ABSTRACT}

This paper presents the results of a bibliographical review of the online literature of the articles published on the theme of Inclusive Education in Sciences/Chemistry in six Brazilian journals in the field of Science/Chemistry Teaching. The digital collection consulted contains 2,472 published papers, in the temporal cut from 2006 to 2019 . Only 37 articles related to the theme were found in the last ten years. The initial selection of the papers was done by reading titles and abstracts of each journal and issue, including special ones. The 37 publications that fit the theme were read in full, and were qualified, quantified and grouped into tables and percent graphs, in order to identify the periodicity of the publications, and taking into account the amount of papers over the years, the location of author's affiliations, educational level, thematic focus and kinds of impairment considered. By means of a quanti-qualitative approach, we have verified: (i) low annual growth rate of publications; (ii) concentration of publications in Brazil's midwestern region; (iii) prevalence of higher education students as subjects of research; (iv) teacher training as a major thematic focus, and ( $v$ ) prevalence of studies on visual impairment instead of other types. The panorama outlined reveals the need for an increase in the proposal and dissemination of activities and didactic materials that help teachers at all levels of education to deal with the demands that are presented in the scope of inclusive education.

Keywords: Inclusive Education; Chemistry Teaching; Literature Review.

\section{RESUMEN}

El presente artículo presenta los resultados de una revisión bibliográfica de la literatura online de los artículos publicados sobre la temática Educación Inclusiva en Ciencias/Química en seis periódicos brasileños dirigidos a la Enseñanza de Ciencias/Química. El acervo digital consultado totalizó 2.472 publicaciones, entre 2006 a 2019. Solo hubo 37 publicaciones relacionadas con el tema. La selección de los artículos fue realizada a partir de la lectura de los títulos y resúmenes de cada revista y volumen publicado, incluyendo ediciones especiales. Las 37 publicaciones que se encuadran en la temática fueron leídas, calificadas, cuantificadas y agrupadas en tablas y gráficos porcentuales, a fin de identificar la periodicidad de las publicaciones y teniendo en cuenta la cantidad de artículos a lo largo de los años, la ubicación de las instituciones de origen de los autores, el nivel de enseñanza, el enfoque temático y los tipos de deficiencias consideradas. Por medio de un enfoque cuantitativo, verificamos: (i) bajo crecimiento en la tasa anual de publicaciones; (ii) concentración de publicaciones en la región centro-oeste brasileña; (iii) predominio de estudiantes de enseñanza superior como sujetos de investigación; (iv) la formación de profesores como enfoque temático mayoritario; (v) predominio de estudios sobre deficiencia visual en detrimento de otros tipos. El panorama delineado revela la necesidad de una ampliación en la proposición y divulgación de actividades y materiales didácticos que ayuden a los profesores en todos los niveles de enseñanza a lidiar con las demandas que se presentan en el ámbito de la educación inclusiva.

Palabras clave: Educación Inclusiva; Enseñanza de Química; Revisión de Literatura. 
http://dx.doi.org/10.5902/1984686X36887

\section{Introdução}

A educação inclusiva vem ganhando espaço nas discussões do cenário educacional, principalmente no âmbito da formação de professores de Química/Ciências, uma vez que a demanda de alunos com deficiências auditiva, visual, cognitiva e mental no ensino regular tem aumentado gradativamente, ocasionando receios e insegurança nos professores que atuam nestas instituições de ensino a respeito dessa realidade.

Diante da perspectiva de educação inclusiva pautada nos documentos oficiais, como a Constituição Federal Brasileira, a Lei de Diretrizes e Bases da Educação (BRASIL, 1996), o Estatuto da Pessoa com Deficiência (BRASIL, 2015), a Declaração de Salamanca (UNESCO, 1994) ou o Plano Nacional de Educação (BRASIL, 2014), entre outras leis, decretos, portarias, resoluções, documentos nacionais e internacionais, que designam e garantem esse tipo de educação gratuitamente nas três modalidades de ensino fundamental, médio e superior, as escolas e as universidades públicas precisam se adaptar física e pedagogicamente, reformulando sua infraestrutura e seus currículos a fim de oferecer a todos os seus discentes um ensino que propicie sua formação enquanto cidadãos e/ou profissionais.

Nossa experiência como bolsistas de iniciação à docência e coordenadores do Projeto Institucional de Bolsa de Iniciação à Docência (PIBID) nos apresentou um pouco da complexidade no que diz respeito à mediação pedagógica para com os estudantes deficientes. Isto porque, em todas as escolas em que o programa atuou, encontramos estudantes com deficiências comuns como surdez, baixa visão ou deficiências físicas, assim como diversos tipos de síndromes, tais como as de Down, Lenox-Gastaut, EhlersDanlos, Goldenhar, Dandy-Walker e, ainda, transtornos como os do espectro autista (TEA), Déficit de Atenção com Hiperatividade - TDAH e Transtorno Desafiador Opositivo - TDO.

Embora haja um número considerável de estudantes com deficiências nas escolas, os avanços na questão da inclusão em sala de aula ainda acontecem a passos lentos, tanto no ensino básico quanto no superior, visto que a maioria dos profissionais que estão atuando não possuem a formação necessária, como apontado também na literatura (ULIANA; MÓL, 2017; VILELA-RIBEIRO; BENITE, 2010).

A educação inclusiva exige dos docentes tanto capacitação especializada como formação continuada, além do trabalho em conjunto com outros profissionais da área como intérpretes e centros especializados na educação inclusiva, que auxiliem o 
http://dx.doi.org/10.5902/1984686X36887

professor na produção, desenvolvimento e aplicação de metodologias de ensino e materiais didáticos que possam dar suporte ao processo de ensino-aprendizagem dos educandos com deficiências. Para o Ensino de Química, a inclusão representa um grande desafio dados o alto grau de abstração dos conceitos, a presença marcante de elementos visuais relacionados ao fazer científico, a exemplo de gráficos, tabelas e equações (BENITE, A. M. C. et al., 2014) e a existência de linguagem e terminologia específicas da Química (SOUSA; SILVEIRA, 2012).

O processo de inclusão deve ter em pauta diversos fatores, como: a estrutura das escolas, a organização pedagógica, a disponibilidade de profissionais que acompanhem os alunos com deficiência, preparação dos professores, entre outros (RADMANN; PASTORIZA, 2016). Vilela-Ribeiro e Benite (2010) apontam a importância e necessidade de formação inicial dos professores tanto de ciências quanto de outras áreas do conhecimento, que deve promover, além da redefinição de conceitos, a obtenção de conhecimentos específicos sobre a realidade inclusiva, capacitando os profissionais a lidarem tanto com alunos com necessidades especiais quanto com os alunos advindos de realidades diversas.

Neste contexto, o presente artigo tem como objetivo apresentar uma revisão da literatura online de seis periódicos nacionais da área de ensino de Ciências/Química nos últimos dez anos (no período de 2006 a 2016), mapeando e analisando quantitativa e qualitativamente como os pesquisadores, professores e alunos nos três níveis de formação (fundamental, médio e superior) vêm debatendo e dando ênfase à temática da Educação Inclusiva no Ensino de Química/Ciências na Rede Pública de Ensino.

\section{Reflexões acerca da educação inclusiva}

O acesso de alunos com deficiência às turmas do ensino regular é um direito estabelecido pela Lei de Diretrizes e Bases (LDB n 9394/96). Tal direito impõe grandes desafios para o sistema escolar e exige uma marcante demanda de competências profissionais dos professores que recebem tais alunos em suas turmas. A fim de refletirmos sobre os desafios da inclusão, é importante conhecer os diferentes aspectos que envolvem os saberes docentes necessários a um fazer pedagógico capaz de contemplar a diversidade e garantir não somente a acessibilidade do conhecimento, mas também a participação de todos os alunos, com deficiência ou não, em todos os espaços sociais. de maneira integrada. Para tanto, apresentamos a seguir algumas concepções a 
http://dx.doi.org/10.5902/1984686X36887

respeito da educação inclusiva de uma maneira geral, de modo a auxiliar a análise dos trabalhos encontrados na revisão da literatura específica do ensino de Química, objeto desta pesquisa.

Um excelente histórico das relações entre educação e as distintas concepções sobre deficiência é apresentado por Raposo e Mól (2011), desde as primeiras iniciativas francesas em direção à educação de pessoas com deficiências até as orientações educacionais contemporâneas vigentes no Brasil, a exemplo das Diretrizes Operacionais para o Atendimento Educacional Especializado na Educação Básica, que regem as ações voltadas à Educação Especial no âmbito escolar.

Neste sentido, é importante resgatar a própria concepção de inclusão e o que se espera da escola na promoção de uma educação inclusiva. Mantoan (2003) ressalta a importância de distinguir a integração escolar, entendida como a justaposição do ensino especial ao regular, da inclusão, que deve prever a inserção desde o começo da vida escolar, de forma completa e sistemática de todos os alunos no ensino regular:

(...) Quanto à inclusão, esta questiona não somente as políticas e a organização da educação especial e da regular, mas também o próprio conceito de integração. Ela é incompatível com a integração, pois prevê a inserção escolar de forma radical, completa e sistemática. Todos os alunos, sem exceção, devem frequentar as salas de aula do ensino regular. $O$ objetivo da integração é inserir um aluno, ou um grupo de alunos, que já foi anteriormente excluído, e o mote da inclusão, ao contrário, é o de não deixar ninguém no exterior do ensino regular, desde o começo da vida escolar. (MANTOAN, 2003)

Nesta mesma linha de pensamento, a Declaração de Salamanca tem como princípio que a educação inclusiva não é uma ação da educação especial, mas sim uma obrigação da escola comum (UNESCO, 1994). Desse modo, a inclusão exige uma mudança do paradigma educacional, pois deve eliminar a subdivisão da educação nas modalidades regular e especial:

Escolas inclusivas devem reconhecer e responder às necessidades diversas de seus alunos, acomodando ambos os estilos e ritmos de aprendizagem e assegurando uma educação de qualidade a todos através de um currículo apropriado, arranjos organizacionais, estratégias de ensino, uso de recurso e parceria com as comunidades. (UNESCO, 1994)

No âmbito da legislação brasileira, a LDB n 9394/96 (BRASIL, 1996) estabelece, em seu capítulo $\mathrm{V}$, artigo 59, que os sistemas de ensino devem assegurar aos educandos com necessidades especiais: 
http://dx.doi.org/10.5902/1984686X36887

I - currículos, métodos, técnicas, recursos educativos e organização específicos, para atender às suas necessidades;

(...)

III - professores com especialização adequada em nível médio ou superior, para atendimento especializado, bem como professores do ensino regular capacitados para a integração desses educandos nas classes comuns. (BRASIL, 1996)

Neste sentido, Glat e Nogueira (2003) alertam que o primeiro obstáculo a ser transposto é o fato de que a prática pedagógica dos professores está impregnada pela concepção de que existiria um processo de ensino-aprendizagem "normal", que poderia ser abordado por uma metodologia universal de ensino, e que alunos com alguma deficiência deveriam ser considerados "especiais" e, portanto, deveriam passar por um processo de ensino-aprendizagem diferenciado. Em contrapartida, Silva (2009) chama a atenção para o fato de que não se pode ignorar a complexidade decorrente dos diferentes tipos de deficiências e, consequentemente, das diversas formas de intervenção necessárias, de modo que a escolarização das pessoas com deficiência demanda um conjunto de saberes próprios.

No caso específico do ensino de Ciências, a capacitação de professores do ensino regular para incluir o crescente número de alunos com necessidades especiais matriculados no ensino regular às suas classes constitui um desafio ainda maior, uma vez que implica o ensino de fenômenos que podem demandar experiências sensoriais não disponíveis para alunos com determinadas deficiências (BASTOS, LINDEMANN, REYES, 2016). Naturalmente, há diferentes maneiras de se ensinar e aprender um mesmo fenômeno, mas os professores precisam ser treinados na utilização de alternativas de se apresentar, por exemplo, conteúdos que exijam visualização (SOUSA; SILVEIRA, 2012), como identificação da ocorrência de reações ou geometria molecular a alunos cegos, ou nomenclatura de compostos químicos ou outros conteúdos que fazem extenso uso da terminologia química para alunos que muitas vezes ainda estão em processo de aquisição da Língua Brasileira de Sinais e terão de, ao mesmo tempo, aprender termos científicos em português, formar conceitos espontâneos acerca dos fenômenos em estudo, adquirir conceitos científicos e articulá-los (OLIVEIRA; BENITE, 2015a). 
http://dx.doi.org/10.5902/1984686X36887

\section{Metodologia}

Foram selecionados seis periódicos nacionais da área de ensino de Química/Ciências, embasados nos seguintes critérios de seleção: periódicos voltados para divulgação da pesquisa no ensino de Química/Ciências reconhecidos nacionalmente, apresentando avaliação nível A ou B na área de Educação segundo o Qualis do Sistema de Avaliação e Qualificação da Coordenação de Aperfeiçoamento de Pessoal de Nível Superior (CAPES) e dispondo de um acervo online de fácil acesso para consulta. São eles: Química Nova na Escola; Investigações em Ensino de Ciências; Ciência \& Educação; Revista Brasileira de Pesquisa em Educação em Ciências; Ensaio: Pesquisa em Educação em Ciências e Revista Brasileira de Ensino de Química. Paralelo à etapa de seleção dos periódicos, um levantamento bibliográfico foi realizado no acervo virtual de cada periódico, incluindo edições especiais, nos últimos dez anos, que corresponde ao recorte temporal do ano de 2006 a 2019, sobre o tema: "Educação Especial/Inclusiva no ensino de Ciências/Química" a partir das seguintes palavras chaves: inclusão, ensino inclusivo, formação inclusiva, desafios da formação inclusiva, educação especial, libras, deficiência visual, surdez, metodologias inclusivas e avaliação inclusiva, todas associadas ao termo ensino de ciências ou ensino de química. No Quadro 1 apresentamos os principais dados relacionados aos periódicos investigados.

Quadro 1 - Descrição dos periódicos investigados neste trabalho.

\begin{tabular}{|l|c|c|c|}
\hline \multicolumn{1}{|c|}{ Revistas } & $\begin{array}{c}\text { Total de } \\
\text { artigos }\end{array}$ & Volumes & Números \\
\hline Química Nova na Escola & 553 & 23 ao 41 & $\begin{array}{c}1 \text { ao } 4 / 2 \text { Ed. } \\
\text { Especiais }\end{array}$ \\
\hline Investigação em Ensino de Ciências & 402 & 11 ao 24 & 1 ao 3 \\
\hline Ciência \& Educação & 668 & 12 ao 25 & 1 ao 4 \\
\hline $\begin{array}{l}\text { Revista Brasileira de Pesquisa em } \\
\text { Educação em Ciências }\end{array}$ & 389 & 6 ao 19 & 1 ao 3 \\
\hline $\begin{array}{l}\text { Ensaio: pesquisa em Educação em } \\
\text { Ciências }\end{array}$ & 314 & 8 ao 21 & $\begin{array}{c}1 \text { ao 3 / } 1 \text { Ed. } \\
\text { Especial }\end{array}$ \\
\hline Revista Brasileira de Ensino de Química & 166 & 1 ao 13 & 1 ao 2 \\
\hline
\end{tabular}

Fonte: Autores da Pesquisa, 2019.

A seleção inicial dos artigos foi realizada a partir da leitura dos títulos de cada publicação que teve como base um mapeamento detalhado (quanti-qualitativo) 
http://dx.doi.org/10.5902/1984686X36887

(CRESWELL, 2007) e os seguintes critérios de avaliação: estar publicado nos periódicos no período que compreende os anos de 2006 a 2019 e estar relacionado direta ou indiretamente com a temática inclusiva no ensino de Química/Ciências. Atribuídos tais critérios, foram realizadas as leituras dos resumos e consecutivamente a leitura na íntegra de cada artigo. Em seguida, as publicações que se enquadravam na temática e nos critérios estabelecidos foram listadas, quantificadas e separadas por periódicos, como demonstra o Quadro 2.

Quadro 2 - Quantificação dos artigos selecionados.

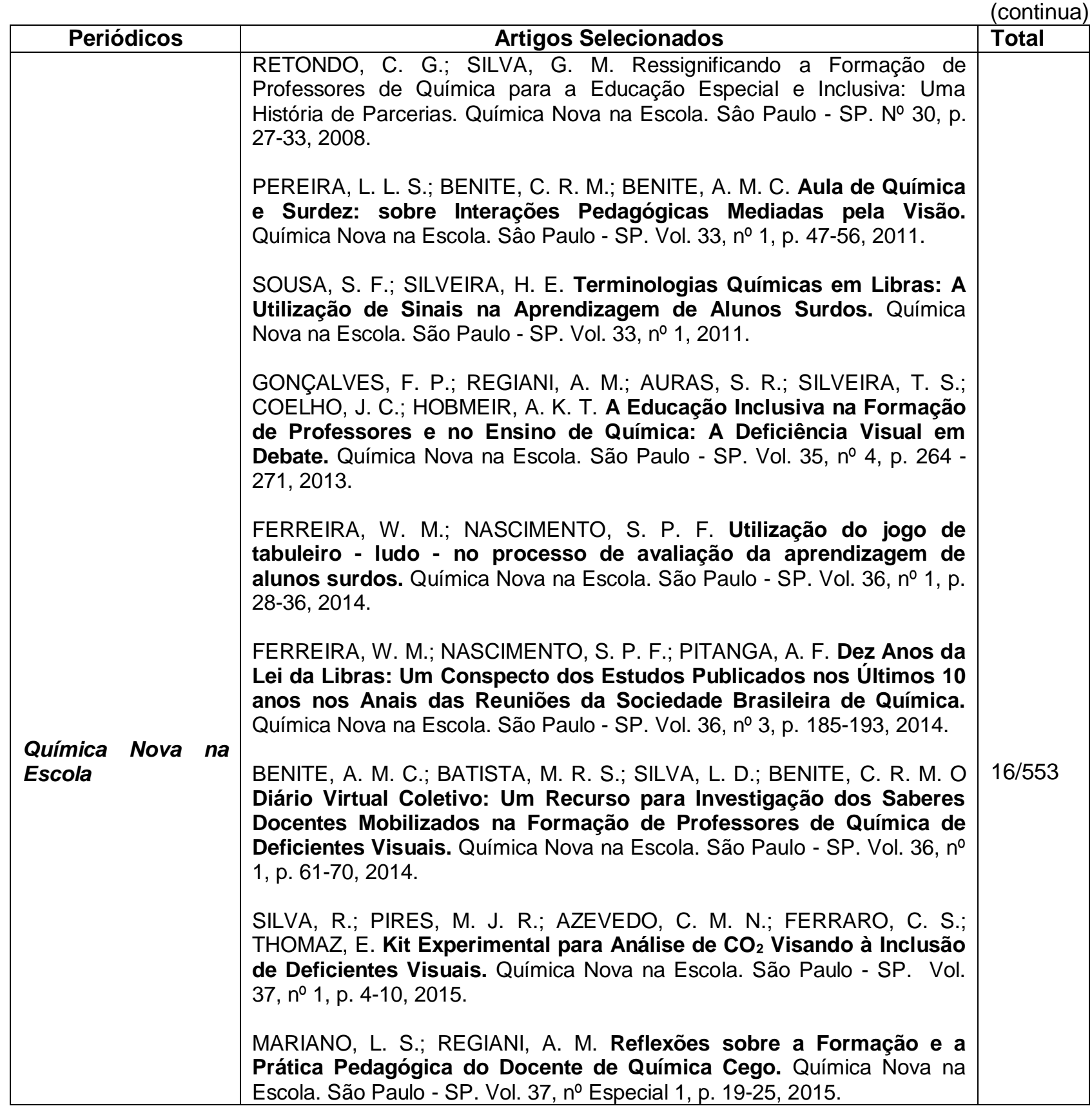


Quadro 2 - Quantificação dos artigos selecionados.

(continuação)

\begin{tabular}{|c|c|c|}
\hline $\begin{array}{c}\text { Química Nova na } \\
\text { Escola }\end{array}$ & $\begin{array}{l}\text { ANDRADE, J. J. Evidências para Além do Enxergar: Vivências e } \\
\text { Significação do Conceito de Reação Química entre Alunos com } \\
\text { Baixa Visão. Química Nova na Escola. São Paulo - SP. Vol. 37, no 2, } \\
\text { p. 143-152, } 2015 . \\
\text { VOOS, I. C.; GONÇALVES, F. P. Tecnologia assistiva e ensino de } \\
\text { química: reflexões sobre o processo educativo de cegos e a } \\
\text { formação docente. Química Nova na Escola. São Paulo - SP. Vol. 38, } \\
\text { p. 297-305, 2016. } \\
\text { BENITE, C. R. M.; BENITE, A. M. C.; BONOMO, F. A. F.; VARGAS, G. } \\
\text { N.; ARAÚUO, R. J. S.; ALVES, D. R. A Experimentação no Ensino de } \\
\text { Química para deficientes visuais com o uso de tecnologia } \\
\text { assistiva: o termômetro vocalizado. Química Nova na Escola. São } \\
\text { Paulo - SP. Vol. 39, no 3, p. 245-249, 2017. } \\
\text { FERNANDES, J. M.; FREITAS-REIS, I. Estratégia Didática Inclusiva } \\
\text { a Alunos Surdos para o Ensino dos Conceitos de Balanceamento } \\
\text { de Equações Químicas e de Estequiometria para o Ensino Médio. } \\
\text { Química Nova na Escola. São Paulo - SP. Vol. 39, no 2, p. 186-194, } \\
\text { 2017. } \\
\text { FERNANDES, T. C.; HUSSEIN, F. R. G. S.; DOMINGUES, R. C. P. R. } \\
\text { Ensino de química para deficientes visuais: a importância da } \\
\text { experimentação num enfoque multissensorial. Química Nova na } \\
\text { Escola. São Paulo - SP. Vol. 39, no 2, p. 195-203, 2017. } \\
\text { PHILIPPSEN, E. A.; GAUCHE, R. TUXI, P.; FELTEN, E. F. Ensino de } \\
\text { Química e Codocência: Interdependência Docente/Tradutor e } \\
\text { Intérprete de Língua de Sinais. Química Nova na Escola. São Paulo - } \\
\text { SP. Vol. 41, no 2, p. 162-170, 2019. } \\
\text { SILVEIRA, R. A.; GONÇALVES, F. P. Compreensões sobre a } \\
\text { Cegueira e as Atividades Experimentais no Ensino de Química: } \\
\text { Quais as Relações Possíveis? Química Nova na Escola. São Paulo - } \\
\text { SP. Vol. 41, no 2, p. 190-199, 2019. }\end{array}$ & $16 / 553$ \\
\hline $\begin{array}{l}\text { Investigações em } \\
\text { Ensino de Ciências }\end{array}$ & $\begin{array}{l}\text { PEREIRA, L. L. S.; BENITE, A. M. C. Redes Sociais como Espaço de } \\
\text { Interações Discursivas sobre a Formação de Professores de Ciências } \\
\text { para a Educação Inclusiva. Investigaços em Ensino de Ciências. Vol. } \\
\text { 13, nº 3, 2012. } \\
\text { COSTA, A. M. F.; LIMA, S. A.; STADLER, R. C. L.; CARLETTO, M. R. A } \\
\text { Importância da Tutoria no Ensino de Ciências Naturais com Alunos } \\
\text { Especiais. Investigações em Ensino de Ciências. Vol. 20, no 1, p. 127-141, } \\
2015 . \\
\text { PASSOS, A. M.; ARRUDA, S. M.; PASSOS, M. M. Análise das Relações } \\
\text { Docente em Sala de Aula com Perspectivas de Ser Inclusiva. } \\
\text { Investigações em Ensino de Ciências. Vol. 20, no 3, p. 84-115, 2015. } \\
\text { NOGUEIRA, E. P.; BARROSO, M. C. S.; SAMPAIO, C. G. A Importância } \\
\text { da Libras: Um Olhar Sobre o Ensino de Química a Surdos. } \\
\text { Investigações em Ensino de Ciências. Vol. 23, nº 2, p. 49-64, 2018. } \\
\text { BERTOLIN, F. N.; OLIVEIRA, O. B. Relações com o Saber na Educação } \\
\text { Especial: Um Estudo de Ciências. Investigações em Ensino de Ciências. } \\
\text { Vol. 23, no 2, p. 171-186, 2018. }\end{array}$ & $5 / 402$ \\
\hline
\end{tabular}


Quadro 2 - Quantificação dos artigos selecionados.

(continuação)

\begin{tabular}{|c|c|c|}
\hline $\begin{array}{l}\text { Ciência } \\
\text { Educação }\end{array}$ & $\begin{array}{l}\text { RIBEIRO, E. B. V.; BENITE, A. M. C. A Educação Inclusiva na } \\
\text { Percepção dos Professores de Química. Ciência \& Educação. Bauru - } \\
\text { SP. Vol. 16, no 3, p. 585-594, 2010. } \\
\text { REGIANI, A. M.; MÓL, G. S. Inclusão de uma Aluna Cega em um Curso } \\
\text { de Licenciatura em Química. Ciência \& Educação. Bauru, SP. Vol. 19, no } \\
\text { 1, p. 123-134, 2013. } \\
\text { RIBEIRO, E. B. V.; BENITE, A. M. C. Alfabetização Científica e } \\
\text { Educação Inclusiva no Discurso de Professores Formadores de } \\
\text { Professores de Ciências. Ciência \& Educação. Bauru - SP. Vol. 19, no } \\
\text { 3, p. 781-794, 2013. } \\
\text { OLIVEIRA, W. D.; BENITE, A. M. C. Aulas de Ciências para Surdos: } \\
\text { Estudos sobre a Produção do Discurso de Intérpretes de LIBRAS e } \\
\text { Professores de Ciências. Ciência \& Educação. Bauru - SP. Vol. 21, no 2, } \\
\text { p. 457-472, 2015. } \\
\text { PEREIRA, L. L. S.; BENITE, C. R. M.; PADILHA, J. C.; MENDES, M. L.; } \\
\text { RIBEIRO, E. B. V.; BENITE, A. M. C. Trajetória da Formaçãa de } \\
\text { Professores de Ciências para Educação Inclusiva em Goiás, Brasil, } \\
\text { sob à ótica de Participantes de uma Rede Colaborativa. Ciência \& } \\
\text { Educação. Bauru - SP. Vol. 21, no 2, p. 473-491, 2015. } \\
\text { CAMARGO, E. P. Inclusão Social, Educação Inclusiva e Educação } \\
\text { Especial: enlaces e desenlaces. Ciência \& Educação. Bauru - SP. Vol. } \\
\text { 23, no 1, 2017, } \\
\text { PASSOS, A. M.; PASSOS, M. M.; ARRUDA, S. M. Uma Análise das } \\
\text { Ações em Sala de Aula em que estão Presentes Estudantes com } \\
\text { Deficiência Visual. Ciência \& Educação. Bauru - SP. Vol. 23, no 2, p. 541- } \\
\text { 556, 2017. } \\
\text { sOFIATO, C. G.; SANTANA, R. S. O Ensino de Sciencias Naturaes e os } \\
\text { alunos Surdos do Século XIX. Ciência \& Educação. Bauru - SP. Vol. 25, } \\
\text { no 2, p. 333-351, 2019. }\end{array}$ & 2/303 \\
\hline $\begin{array}{ll}\text { Revista Brasileira } \\
\text { de Pesquisa } & \text { em } \\
\text { Educação } & \text { em } \\
\text { Ciências } & \end{array}$ & $\begin{array}{l}\text { BENITE, A. M. C.; PEREIRA, L. L. S.; BENITE, C. R. M.; PROCÓPIO, M. } \\
\text { V. R; FRIEDRICH, M. Formação de Professores de Ciências em Rede } \\
\text { Social: Uma Perspectiva Dialógica na Educação Inclusiva. Revista } \\
\text { Brasileira de Pesquisa em Educação em Ciências. Vol. 9, no } 3,2009 \text {. } \\
\text { SILVA, M. D.; GONÇALVES, F. P.; MARQUES, C. A. Práticas } \\
\text { pedagógicas em Ciências da Natureza nos anos iniciais do ensino } \\
\text { fundamental com estudante cegos. Revista Brasileira de Pesquisa em } \\
\text { Educação em Ciências. Vol. 15, ํo 3, } 2015 \text {. } \\
\text { OLIVEIRA, W. D.; BENITE, A. M. C. Estudos sobre a relação entre o } \\
\text { intérprete de LIBRAS e o professor: implicações para o ensino de } \\
\text { ciências. Revista Brasileira em Ensino em Ciências. Vol. 15, no } 3 \text {, } 2015 \text {. } \\
\text { PAULA, T. E.; GUIMARÃES, O. M.; SILVA, C. S. Necessidades } \\
\text { Formativas de Professores de Química para a Inclusão de Alunos } \\
\text { com Deficiência Visual. Revista Brasileira de Pesquisa em Educação em } \\
\text { Ciências. Vol. 17, no } 3 \text {, p. 853-881, } 2017 \text {. }\end{array}$ & 2/247 \\
\hline
\end{tabular}


Quadro 2 - Quantificação dos artigos selecionados.

(conlcusão)

\begin{tabular}{|c|c|c|}
\hline $\begin{array}{l}\text { Ensaio: Pesquisa } \\
\text { em Educação em } \\
\text { Ciências }\end{array}$ & $\begin{array}{l}\text { LIPPE, E. O.; ALVES, F. S.; CAMARGO, E. P. Análise do Processo } \\
\text { Inclusivo em uma Escola Estadual no Município de Bauru: A voz de } \\
\text { um Aluno com deficiência visual. Ensaio: Pesquisa em Educação em } \\
\text { Ciências. Vol. 14, no 02, p. 81-94, } 2012 \text {. }\end{array}$ & $2 / 303$ \\
\hline $\begin{array}{l}\text { Revista Brasileira } \\
\text { de Ensino de } \\
\text { Química }\end{array}$ & $\begin{array}{l}\text { SILVA, D. M.; SILVA, K. M. Deficiência Visual: o desafio da formação } \\
\text { de professores. Revista Brasileira de Ensino de Química. Vol. 10, no 2, p. } \\
21-28,2015 . \\
\text { AZEVEDO, A. C.; PEREIRA, L. F.; RIBEIRO, M. E. N. P. O Perfil Docente } \\
\text { na Perspectiva da Educação Inclusiva no Curso de Licenciatura em } \\
\text { Química. Revista Brasileira de Ensino de Química. Vol. 11, no 1, p. 52-59, } \\
2016 \text {. }\end{array}$ & $2 / 247$ \\
\hline
\end{tabular}

Fonte: Autores da Pesquisa, 2019.

Posteriormente, os trinta e sete artigos publicados e selecionados de acordo com os critérios da análise foram qualificados e agrupados categoricamente em percentuais de periodicidade de ano de publicação (volume, número e edição), região (Norte, Nordeste, Centro-Oeste, Sul e Sudeste), nível de ensino (fundamental, médio e/ou superior), enfoque temático e tipos de deficiências considerados.

\section{Resultados e Discussão}

\section{Evolução temporal das publicações}

De posse dos dados contabilizados do acervo, constatamos que, de 2.492 artigos publicados, apenas 37 estavam relacionados ao tema, correspondendo a apenas 1,5\% do total de publicações. Como pode ser observado no Figura 1, nos anos de 2006 e 2007 não houve publicação de artigos relacionados à temática Ensino Inclusivo de Química/Ciências em nenhum dos periódicos selecionados. A primeira publicação no período observado se deu no ano de 2008, intitulada de Ressignificação da Formação dos Professores de Química para a Educação Especial e Inclusiva numa perspectiva histórica de parcerias, na revista Química Nova na Escola (QNEsc), pelos autores Retondo e Silva (2008). Nos anos seguintes, 2009 e 2010, notamos que o número de artigos se manteve constate, com uma publicação anualmente em Revista Brasileira de Ensino de Química e Ciência \& Educação. Em 2011, a QNEsc publica dois artigos, seguida pela Ensaio: Pesquisa em Educação em Ciências, com apenas uma publicação. 
http://dx.doi.org/10.5902/1984686X36887

No ano de 2012, a Investigações em Ensino de Ciências e a Ensaio: Pesquisa em Educação em Ciências, publicam um artigo cada. No ano seguinte (2013), a Ciência \& Educação apresenta mais duas publicações, enquanto a QNEsc divulga uma publicação. Porém, no ano posterior (2014), a QNEsc assume a liderança, com três publicações. Contudo no ano de 2015, percebe-se um aumento significativo de publicações em cinco dos periódicos selecionados (QNEsc, Investigações em Ensino de Ciências, Ciência \& Educação, Revista Brasileira de Pesquisa em Ensino de Ciências e Revista Brasileira de Pesquisa em Ensino de Química), totalizando 24\% das publicações relacionadas ao tema do recorte temporal.

Figura 1 - Total de publicações por ano

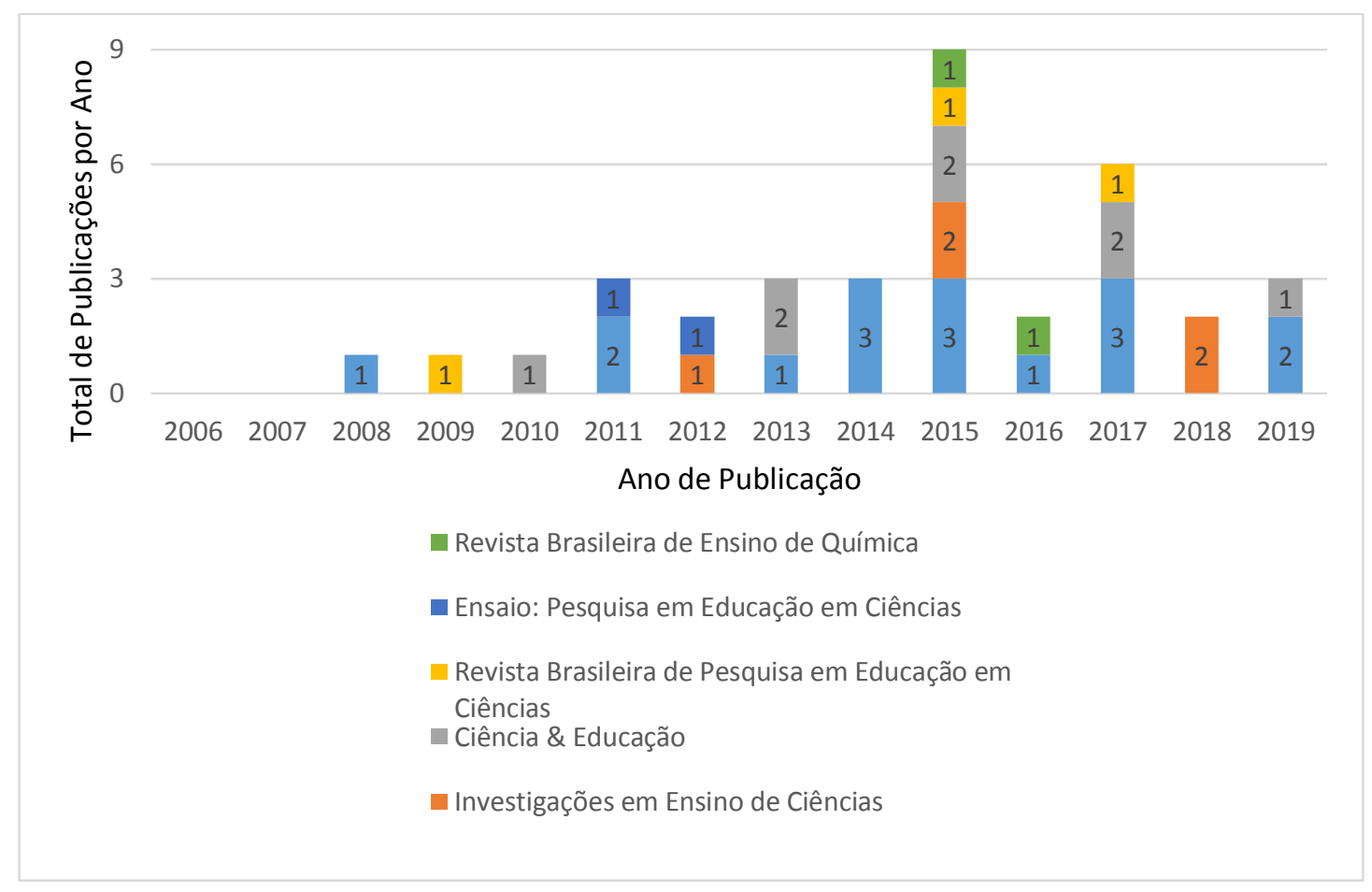

Fonte: Autores da Pesquisa, 2019.

Diante dessa perspectiva a partir dos dados quantitativos, foi possível descrever a progressão de publicações por agrupamento, evidenciando a gradual inserção de trabalhos publicados voltados para o ensino inclusivo de Química/Ciências, como denota a Figura 2. 
http://dx.doi.org/10.5902/1984686X36887

Figura 2 - Agrupamento das publicações por ano

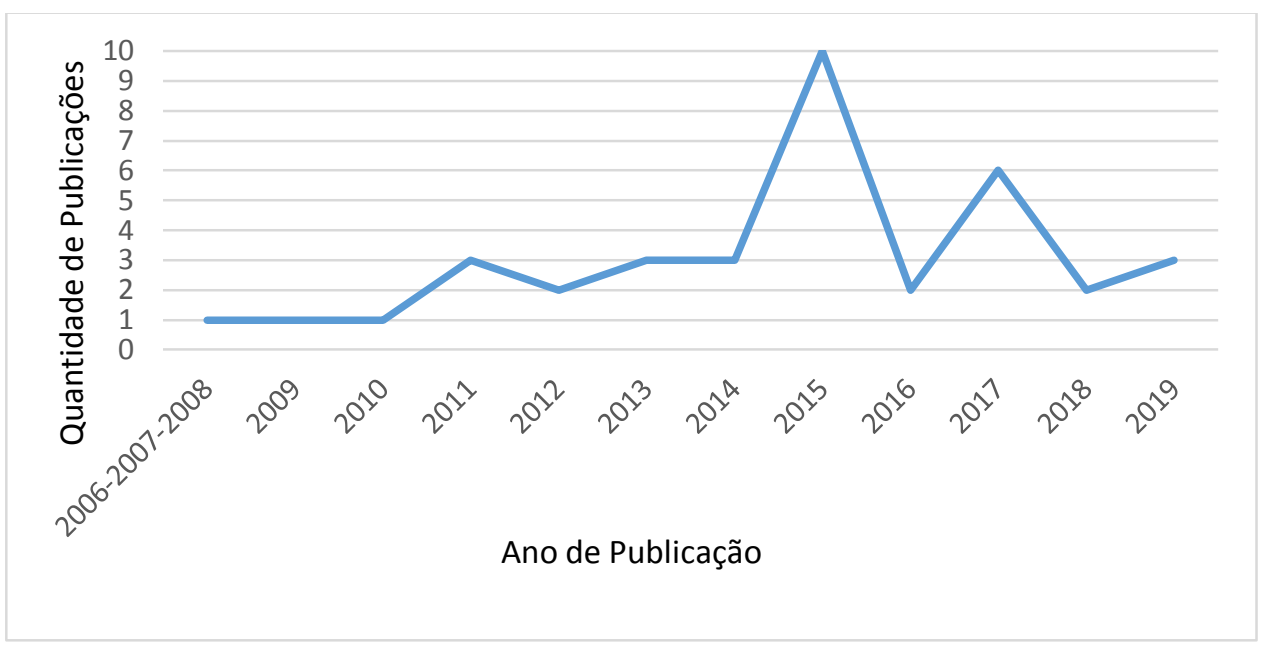

Fonte: Autores da Pesquisa, 2019.

Analisando a Figura 2, notamos um aumento gradativo de publicações entre os anos 2006 e 2015, especialmente no intervalo de 2014 a 2015, onde tivemos crescimento de 3 para 10 publicações. Apesar da não regularidade no aumento da taxa anual de publicação por revistas (2006-2019) como demonstra a Figura 1, é perceptível um aumento no número de pesquisadores envolvidos com a temática, considerando autor principal e coautores, revelando que, dos 37 artigos publicados, temos 30 autores principais diferentes. Ou seja, entre os autores envolvidos com as revistas analisadas, na janela estudada, temos recorrência de publicações na área de 7 autores. Com isso, concluímos que o crescimento no volume de publicações não acompanha o crescimento de pesquisadores na área nos últimos dez anos.

\section{Distribuição regional}

Considerando a região e a instituição de pesquisa a qual os mesmos são vinculados, foi possível descrever de maneira quantitativa na Figura 3 o número de publicações catalogadas por região (Norte, Nordeste, Centro-Oeste, Sul e Sudeste). Com base na Figura 3, a região brasileira que liderou o ranking de artigos publicados, segundo a pesquisa, foi a CentroOeste, com 32\% das publicações, ou seja, 12 (doze) publicações no recorte temporal considerado, com a maioria dos artigos publicados pela Universidade Federal de Goiás. Posteriormente, as regiões Sul, com 27\% (10 publicações) e Sudeste, com 19\% (7 publicações), e, por fim, as regiões Nordeste e Norte, com 13\% e 8\% das publicações (5 e 3), respectivamente. 
http://dx.doi.org/10.5902/1984686X36887

Figura 3 - Quantidade de publicações por região brasileira

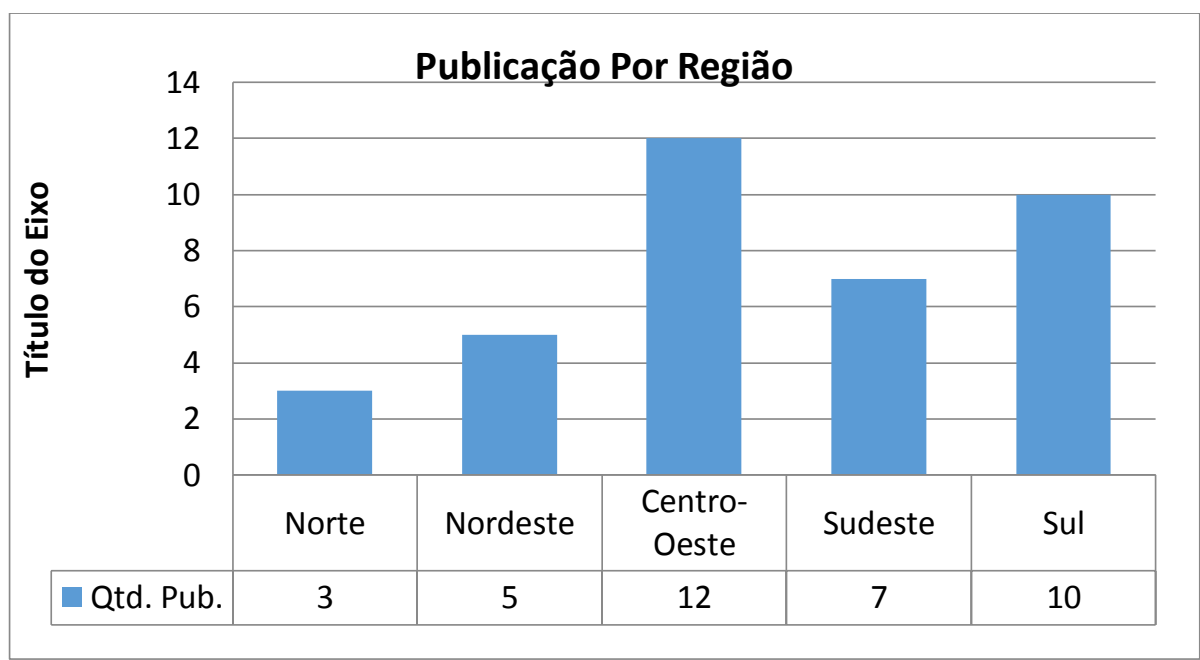

Fonte: Autores da Pesquisa, 2019.

\section{Níveis de ensino}

Alicerçados nos dados anteriores, tais como número de publicações, autores principais recorrentes, região e instituição de pesquisa, investigamos a vertente de estudo selecionada por cada autor em suas publicações, com o intuito de averiguar o nível de ensino abordado (fundamental, médio e/ou superior). Como demonstra a Figura 4, constatamos que 33\% das publicações enquadravam-se no nível de ensino superior, 16\% no ensino fundamental, $27 \%$ associadas ao ensino médio e $24 \%$ relacionadas aos três níveis de ensino.

Figura 4 - Porcentagem das publicações por níveis de ensino

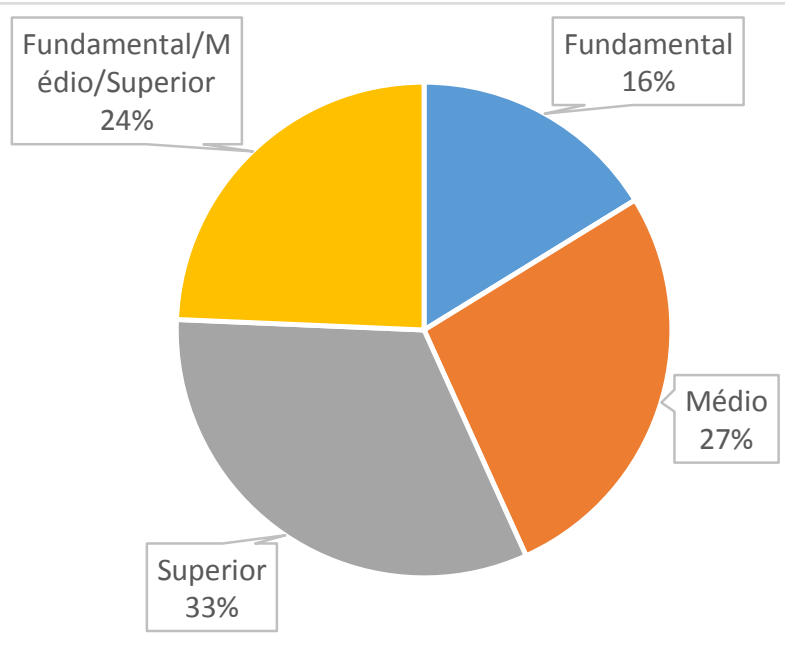

Fonte: Autores da Pesquisa, 2019. 
http://dx.doi.org/10.5902/1984686X36887

\section{Enfoque temático}

Tais publicações foram categorizadas, ainda, com relação ao enfoque temático abordado. A Figura 5 apresenta as quatro temáticas principais observadas: avaliação da aprendizagem, experimentação, formação do professor e avaliação de currículos e programas.

Figura 5 - Número de publicações relacionadas a cada categoria temática

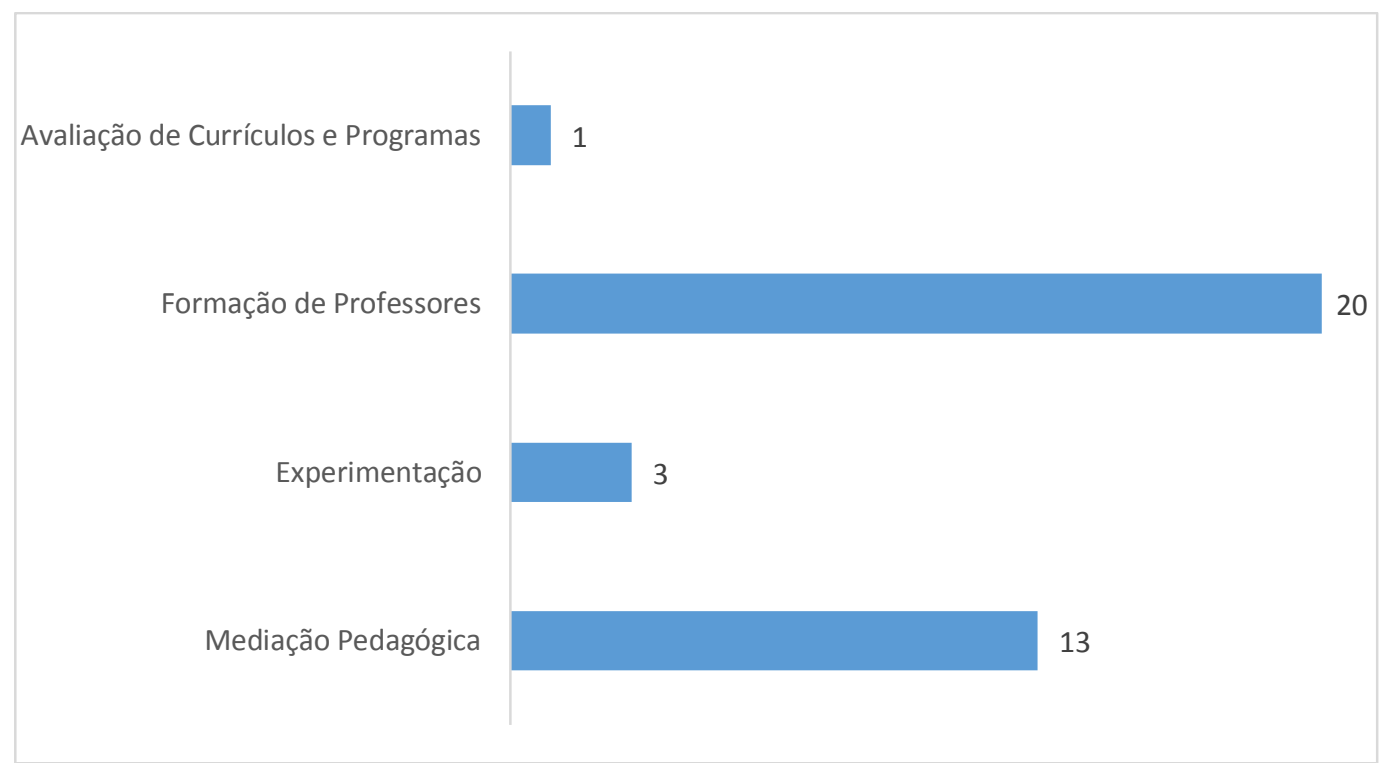

Fonte: Autores da Pesquisa, 2019.

Ao analisarmos as temáticas tratadas nos artigos, percebemos que 20 (vinte) publicações do total de 37 artigos selecionados estão voltadas diretamente para a formação inicial e/ou continuada do professor, totalizando, em termos de porcentagem, $54 \%$ dos trabalhos divulgados. Em seguida, temos que 12 (oito), ou seja, 32\%, das produções foram classificadas como Mediação Pedagógica, que referem-se aos estudos que propuseram conclusões a partir observações feitas pela interação professor/aluno, aluno/intérprete e/ou professor/intérprete ou de conclusões feitas a partir de rodas de conversa entre professores e intérpretes. Com relação à experimentação, apenas 3 artigos se enquadraram diretamente nesta temática, onde propuseram, metodologias experimentais para alunos com deficiência visual. Já na categoria Avaliação de Currículos e Programas, obtivemos $3 \%$ do total de publicações, ou seja, apenas 1 (um) dos 37 trabalhos divulgados encaixou-se nesta temática, expondo as discussões, reflexões e propostas da academia em relação ao ensino inclusivo de Química/Ciências. 
http://dx.doi.org/10.5902/1984686X36887

Em uma análise minuciosa das temáticas mencionadas, pôde-se observar que os artigos na área de Mediação Pedagógica ressaltam a importância da adaptação dos espaços físicos para alunos com deficiência e realçam a importância e necessidade do bilinguismo na sala de aula, com professores capacitados em libras e/ou braile. Na categoria Formação de Professores, os artigos selecionados apresentam uma trajetória dos documentos oficiais legais que garantem a equidade para pessoas com deficiência e apresentam uma análise do atual cenário, além de enfatizar a necessidade da independência didática dos professores, tendo estes a capacidade de desenvolver metodologias e materiais de acordo com as demandas dos diferentes tipos de deficiência.

$\mathrm{Na}$ área de Experimentação, os 3 artigos selecionado apresentam roteiros para construção de kit experimental para alunos com deficiência visual, aliando teoria e prática no ensino de Química. Dado o baixíssimo número de publicações, podemos observar a dificuldade na elaboração de roteiros e a escassez de materiais para alunos com deficiência, especialmente de experimentos que são um recurso didático de reconhecida importância no âmbito do Ensino de Química.

O único artigo sobre a temática "Avaliação de Currículos e Programas" discorre, de uma maneira geral, sobre as dificuldades encontradas por docentes do magistério em apresentar os conteúdos de Química na linguagem de sinais, enfatizando a carência de disciplinas com melhor preparação na área.

Além do enfoque temático da investigação, analisamos também o tipo de deficiência considerado em cada publicação. Observamos que, do total de artigos, 30\% tratam de educação inclusiva de uma maneira geral, 40\% de deficiência visual, 27\% de deficiência auditiva e apenas um artigo apresenta um relato de experiência sobre deficiência intelectual.

\section{Considerações finais}

A presente pesquisa apresentou uma análise das publicações sobre o tema de inclusão no Ensino de Química/Ciências dos periódicos selecionados, no recorte temporal de 2006 a 2019, por abordagem quantitativa e qualitativa, tendo revelado dados interessantes e pouco motivadores. Apesar de garantido o direto de igualdade e inclusão para pessoas com deficiência, o tema ainda vem sendo pouco discutido, como vemos pelo número de publicações nos periódicos analisados. Apesar de ter havido crescimento na taxa anual de publicações, observamos que este crescimento não acontece de 
http://dx.doi.org/10.5902/1984686X36887

maneira recorrente ao longo dos anos. Além disso, apesar de observarmos novos autores visto que, dos 37 artigos analisados, 30 são de diferentes autores e 7 de autores recorrentes, já envolvidos em pesquisas na temática.

Observamos ainda que a concentração de publicações não segue uma distribuição uniforme entre os estados, sinalizando que o cenário de pesquisas nesta área, na maioria dos estados brasileiros (exceto Centro-Oeste), é escasso.

Por fim, conclui-se, com base nos dados apresentados, que, apesar de haver demanda da sociedade, o tema Inclusão no Ensino, especificamente na área de Ensino de Ciências/Química, ainda é pouco explorado, se compararmos com o número de publicações em outros temas e considerando a demanda urgente da sociedade por profissionais capacitados na área para que se cumpra o direito de igualdade já conquistado em lei.

Vale ressaltar que a LDB n 9394/96 (BRASIL, 1996), Capítulo V, Artigo 59, no Inciso III, afirma que os sistemas de ensino devem assegurar aos educandos com necessidades especiais, professores com especialização adequada em nível médio ou superior, para atendimento especializado, bem como professores do ensino regular capacitados para a integração desses educandos nas classes comuns.

As publicações analisadas no recorte temporal considerado evidenciam as preocupações da comunidade de pesquisa em ensino de ciências sobre formação docente, equidade, avaliação da aprendizagem, currículo, programas e estratégias didáticas, porém ainda é visível que muito se discute e pouco se coloca em prática quando o assunto é ensino de Química/Ciências inclusivo, devido à escassez de profissionais que se dediquem exclusivamente ao tema e à dificuldade de se moldar ao cenário educacional brasileiro.

Refletindo em termos do significado mais profundo da educação inclusiva, que deveria integrar efetivamente estudantes com e sem deficiências, nossos resultados indicam que 0 reconhecido potencial de estratégias didáticas tais como atividades experimentais e jogos didáticos têm de estimular o trabalho em equipe e a aprendizagem colaborativa, o que é ainda pouco explorado em sala de aula.

Para além das mudanças estruturais necessárias para dar acesso à educação de qualidade a todos os estudantes, nos preocupamos em chamar a atenção, com este trabalho, sobre a necessidade de uma inserção mais efetiva da problemática da inclusão nos cursos de formação inicial e continuada dos professores, bem como da divulgação 
http://dx.doi.org/10.5902/1984686X36887

de experiências realizadas no âmbito do ensino de Ciências e de Química entre os professores. São estes os profissionais que estarão na linha de frente do processo inclusivo e precisam estar habilitados para introduzir em sua prática docente metodologias que permitam o tratamento adequado da diversidade encontrada no cotidiano da sala de aula. Mais do que isso, os professores precisam conhecer os fundamentos necessários para que se posicionem criticamente a respeito da educação inclusiva e suas diferentes concepções, bem como frente às políticas públicas que envolvem a questão.

\section{Referências}

BASTOS, Amelia Rota Borges; LINDEMANN, Renata; REYES, Vitoria. Educação inclusiva e o ensino de ciências: um estudo sobre as proposições da área. Journal of Research in Special Educational Needs, v. 16, p. 426-429, 2016.

BENITE, A. M. C. et al. O Diário Virtual Coletivo: Um Recurso para Investigação dos Saberes Docentes Mobilizados na Formação de Professores de Química de Deficientes Visuais. Química Nova na Escola, São Paulo, v. 36, p. 61-70, 2014.

BENITE, A. M. C. et al. Formação de Professores de Ciências em Rede Social: Uma Perspectiva Dialógica na Educação Inclusiva. Revista Brasileira de Pesquisa em Educação em Ciências, Belo Horizonte, v. 9, n. 3, p. 1-21, 2009.

BRASIL. Senado Federal. Estatuto da Pessoa com Deficiência (2015). Disponível em: <http://www.camara.gov.br/sileg/integras/432201.pdf >.Acesso em 11 de ago. de 2017.

BRASIL. Lei de Diretrizes e Bases da Educação Nacional. Lei no 9394/96. 1996.

BRASIL. Política Nacional de Educação: Conhecendo as 20 Metas do Plano Nacional de Educação. 2014.

CRESWELL, John W. Projeto de pesquisa: método qualitativo, quantitativo e misto. $2^{\underline{a}}$ Edição. Porto Alegre: Artmed, 2007, pag. 46-48.

GLAT, Rosana; NOGUEIRA, Mario Lucio de Lima. Políticas educacionais e a formação de professores para a educação inclusiva no Brasil. Caderno do Programa de PósGraduação em Educação da UERJ, Ano 10, n. 1, p. 134-141, 2003.

MANTOAN, Maria Teresa Eglér. Inclusão escolar: o que é? Por quê? Como fazer? São Paulo, Editora Moderna, 2003.

OLIVEIRA, Walquíria Dutra de; BENITE, Anna Maria Canavarro. Aulas de ciências para surdos: estudos sobre a produção do discurso de intérpretes de LIBRAS e professores de ciências. Ciência \& Educação, Bauru, v. 21, p. 457-472, 2015.

RADMANN, Tatiane; PASTORIZA, Bruno Santos. A educação inclusiva no ensino de 
Química. In: Encontro Nacional de Ensino de Química (ENEQ), 18, 2016, Florianópolis.

RAPOSO, Patrícia Neves; MÓL, Gerson de Souza. A diversidade para aprender conceitos científicos: a ressignificação do Ensino de Ciências a partir do trabalho pedagógico com alunos cegos. In.: SANTOS, Wildson Luiz P.; MALDANER, Otávio Aloisio. Ensino de Química em Foco, ljuí, Editora da Unijuí, p. 287-312, 2011.

RETONDO, Carolina Godinho; SILVA, Glaucia Maria. Ressignificando a Formação de Professores de Química para a Educação Especial e Inclusiva: Uma História de Parcerias. Química Nova na Escola. São Paulo, n. 30, p. 27-33, 2008.

SILVA, Lázara Cristina; Políticas públicas e formação de professores: vozes e vieses da educação inclusiva. Tese (Doutorado) - Universidade Federal de Uberlândia, Uberlândia, 2009.

SOUSA, Sinval Fernandes; SILVEIRA, Hélder Eterno. Terminologias Químicas na Libras: a utilização de sinais na aprendizagem de alunos surdos. Química Nova na Escola, v. 33, p. 37-46, 2012.

ULIANA, Marcia Rosa; MÓL, Gerson Souza. O processo educacional de estudante com deficiência visual: uma análise dos estudos de teses na temática. Revista Educação Especial, v. 30, n. 57, p. 145-162, jan./abr. 2017.

UNESCO. Declaração de Salamanca sobre princípios, política e práticas na área das necessidades educativas especiais. Salamanca, 1994.

VILELA-RIBEIRO, Eveline Borges; BENITE, Anna Maria Canavarro. A educação inclusiva na percepção de professores de Química. Ciência \& Educação, Bauru, v. 16, p. 341-350, 2010.

\section{Correspondência}

Patrícia Maria de Sousa Santos - Universidade Federal de Paraíba, Campus I, Lot. Cidade Universitaria, João Pessoa, Paraíba, Brasil.

CEP: $58051-900$

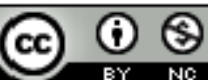

4.0 International (CC BY-NC 4.0) 